\title{
Lack of involvement of mitochondrial factors in caspase activation in a Drosophila cell-free system
}

\author{
JC Means ${ }^{1}$, I Muro ${ }^{1,2}$ and RJ Clem ${ }^{\star, 1}$ \\ 1 Molecular, Cellular and Developmental Biology Program, Division of Biology, \\ Kansas State University, Manhattan, KS 66506, USA \\ 2 Current address: Division of Biology, California Institute of Technology, \\ Pasadena, CA 91125, USA \\ * Corresponding author: RJ Clem, Division of Biology, Kansas State University, \\ 232 Ackert Hall, Manhattan, KS 66506, USA. Tel: 785-532-3172; \\ Fax: 785-532-6653; E-mail: rclem@ksu.edu
}

Received 16.9.05; accepted 19.10.05; published online 02.12.05

Edited by E Baehrecke

\section{Abstract}

Although mitochondrial proteins play well-defined roles in caspase activation in mammalian cells, the role of mitochondrial factors in caspase activation in Drosophila is unclear. Using cell-free extracts, we demonstrate that mitochondrial factors play no apparent role in Drosophila caspase activation. Cytosolic extract from apoptotic $\mathbf{S 2}$ cells, in which caspases were inhibited, induced caspase activation in cytosolic extract from normal S2 cells. Mitochondrial extract did not activate caspases, nor did it influence caspase activation by cytosolic extract. Silencing of Hid, Reaper, or Grim reduced caspase activation by apoptotic cell extract. Furthermore, a peptide representing the amino terminus of Hid was sufficient to activate caspases in cytosolic extract, and this activity was not enhanced by addition of mitochondria or mitochondrial lysate. The Hid peptide also induced apoptosis when introduced into S2 cells. These results suggest that caspase activation in Drosophila is regulated solely by cytoplasmic factors and does not involve any mitochondrial factors.

Cell Death and Differentiation (2006) 13, 1222-1234. doi:10.1038/sj.cdd.4401821; published online 2 December 2005

Keywords: apoptosis; mitochondria; cytochrome c; Drosophila; caspase; hid; reaper; grim; DIAP1

Abbreviations: IAP, inhibitor of apoptosis; Hid, head involution defective; Rpr, reaper; dsRNA, double-stranded RNA; CAT, chloramphenicol acetyl transferase gene; eGFP, enhanced green fluorescent protein; HRP, horseradish peroxidase; RNAi, RNAmediated interference; GST, glutathione-S-transferase

\section{Introduction}

Apoptosis, a type of programmed cell death, is a highly regulated process used to remove unwanted cells in metazoans. Apoptosis is required for normal development, maintenance of tissue homeostasis, and regulation of certain disease states. ${ }^{1,2}$ The key components of the machinery that carries out this evolutionarily conserved process are caspases. Caspases are a group of cysteine proteases that are synthesized as zymogens, but upon receiving an apoptotic signal, the inactive caspases usually undergo proteolytic processing to generate the active form. ${ }^{3}$

In mammals, there are two well-defined pathways that lead to caspase activation, the extrinsic, and intrinsic pathways. ${ }^{4}$ In the intrinsic pathway, a death signal causes the release of cytochrome $c$ from the intermembrane space of mitochondria into the cytosol, where it binds to the adaptor molecule Apaf-1, causing Apaf-1 to undergo a conformational change that allows it to bind ATP and procaspase $-9 .^{5}$ Procaspase- 9 is then activated by dimerization, and activated caspase- 9 cleaves effector caspases such as caspase-3 and caspase7 , which cleave key substrates in the cell, leading to death. ${ }^{6}$ In addition to cytochrome $c$, several other proapoptotic factors are known to be released from the intermembrane space of mammalian cells following apoptotic stimulation, including Smac/DIABLO, AIF, endonuclease G, and HtrA2/Omi. These factors serve to inhibit inhibitor of apoptosis (IAP) proteins, which normally function to inhibit active caspases, and also can induce caspase-independent death. ${ }^{4}$

The role of cytochrome $c$ in the mammalian intrinsic apoptotic pathway is well documented. Addition of cytochrome $c$ and ATP to cytosolic extract is sufficient to cause activation of caspase- $3,{ }^{7}$ and injection of cytochrome $c$ into mammalian cells triggers caspase activation and apoptosis. ${ }^{8}$ Furthermore, cells derived from mouse embryos lacking cytochrome $c$ are severely impaired in the intrinsic death pathway. ${ }^{9}$

In Drosophila, a genetic screen led to the identification of three genes that are involved in developmentally programmed apoptosis: reaper ( $r p r)$, head involution defective (hid), and grim. ${ }^{10}$ The products of each of these genes induce apoptosis via a pathway that requires caspase action. These proapoptotic proteins, along with two other proteins, Sickle ${ }^{11}$ and Jafrac2, ${ }^{12}$ bind to the Drosophila IAP protein DIAP1, and one mechanism by which these proteins promote apoptosis is by disrupting DIAP1-caspase interactions. ${ }^{13}$ Seven Drosophila caspases have been identified, and four of these, DCP-1, DrICE, Dredd, and DRONC, have been implicated in the regulation of apoptosis. ${ }^{14-17}$ In addition, a Drosophila homolog of Apaf-1/CED4, called DARK/Dapaf-1/HAC-1, ${ }^{18}$ has been identified and shown to be required for DRONC activation. $^{19}$

Although the apoptotic machinery in Drosophila appears to be superficially similar to that of mammals, the role of mitochondrial factors in Drosophila apoptosis is unclear. One study found that in Drosophila SL2 cells, induction of apoptosis by overexpression of Reaper or treatment with staurosporine or cycloheximide led to the release of cytochrome $c$ into the cytosol. ${ }^{20}$ However, Varkey et al. ${ }^{21}$ reported that caspase activity or overexpression of Reaper or Grim did not lead to cytochrome $c$ release, but instead led to altered cytochrome $c$ display. Zimmermann et al. ${ }^{22}$ demonstrated that 
after treatment with UV, cycloheximide, or actinomycin D, cytochrome $c$ remained in the mitochondria and when cytochrome $c$ expression was reduced by RNAi, Drosophila cells showed no increased resistance to apoptosis induced by Reaper or Grim. Overexpression of cytochrome $c$ in Drosophila BG2 cells or addition of recombinant cytochrome $c$ to cytosolic BG2 extract did not lead to increased caspase activation or apoptosis. ${ }^{23}$ Genetic analysis of cytochrome $c$ mutants has also led to the conclusion that it is not necessary for caspase activation in Drosophila. Prepupae that were heterozygous for P-element insertions in either or both of the two cytochrome $c$ alleles in Drosophila, $d c 3$, and $d c 4$, or heterozygous for a deficiency that removed both alleles, had reduced levels of cytochrome $c$ but still had normal levels of caspase activity.

Although these previous studies demonstrated that cytochrome $c$ is not necessary for caspase activation, they failed to conclusively rule out whether it can play a role in this process. For example, Dorstyn et al. ${ }^{24}$ also found that incubation of cytosolic extract from BG2 cells with cytochrome $c$ and ATP caused DRONC to become associated with a large molecular weight complex reminiscent of the apoptosome in mammals, suggesting that cytochrome $c$ might be capable of causing caspase activation. ${ }^{24}$ In addition, the potential role of other mitochondrial factors besides cytochrome $c$ in caspase activation has not been investigated in Drosophila. One study has shown that Reaper localizes to mitochondria via its $\mathrm{GH} 3$ domain, and the authors hypothesized that Reaper may induce the release of mitochondrial factors that influence caspase activation, ${ }^{25}$ but evidence in this area is lacking.

In this study, we have investigated the importance of cytochrome $c$ and other mitochondrial factors in caspase activation in Drosophila S2 cell extracts. We report that cytochrome $c$ and other mitochondrial factors are not required for, nor do they appear to influence, caspase activation in S2 cytosolic extracts. Our results instead indicate that one or more of the cytosolic proteins Hid, Reaper, and Grim are both necessary and sufficient to induce caspase activation in S2 cells due to their abilities to inhibit the interaction between DIAP1 and DRONC and to trigger DIAP1 degradation.

\section{Results}

The majority of previous studies that have examined cytochrome $c$ release from mitochondria in Drosophila cells have concluded that cytochrome $c$ is not released from Drosophila mitochondria following apoptotic stimuli. ${ }^{21-24}$ To examine this, we treated S2 cells with UV and at various times after UV treatment samples were harvested and assayed for cytochrome $c$ and DrICE in the mitochondrial (P10) and cytosolic ( 100$)$ fractions by immunoblot analysis. Similar to previous reports, cytochrome $c$ was only detected in the P10 fraction even though caspase activity and processed DrICE were observed in the $\mathrm{S} 100$ fraction (Figure 1a). In contrast, when human 293 cells were UV-irradiated, cytochrome $c$ was released into the $\mathrm{S} 100$ fraction, as is known to occur in mammalian cells (Figure $1 \mathrm{~b}$ ). Cytochrome $c$ release into the
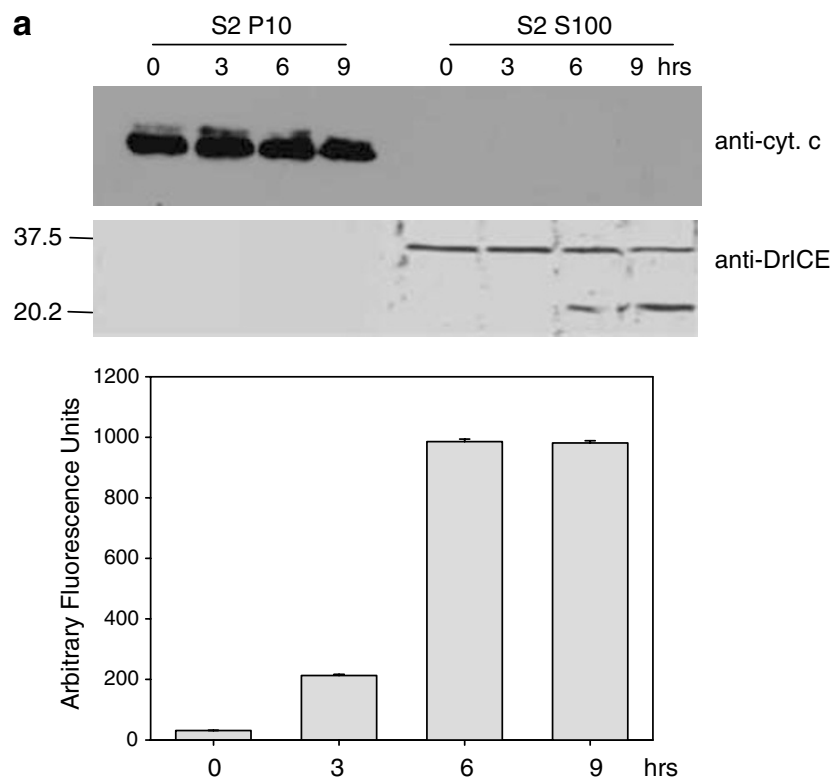

b
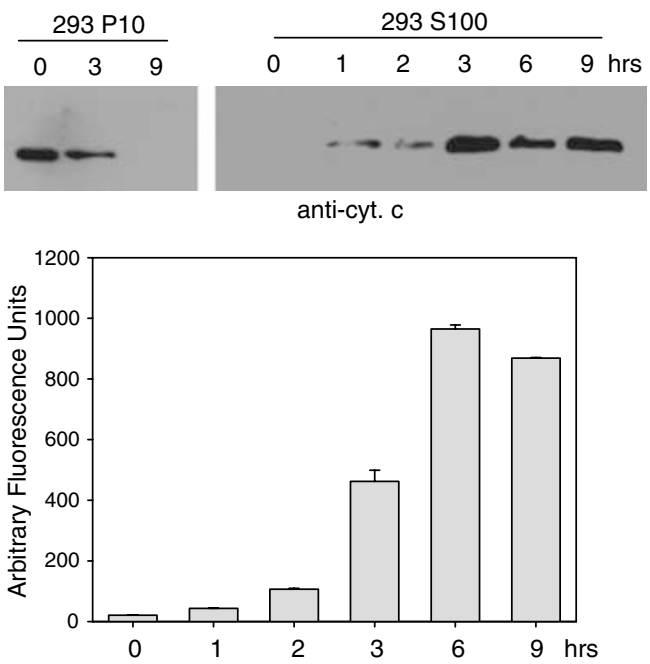

Figure 1 Cytochrome $c$ is not released from S2 cell mitochondria during UV-induced apoptosis. (a) Drosophila S2 cells were UV irradiated and at the indicated times the P10 and S100 fractions were isolated and analyzed by immunoblotting with anti-cytochrome $c$ and anti-DrICE antibodies (above). Caspase activity was measured in S100 from UV-treated cells using DEVD-afc as substrate (below). (b) Human 293 cells were UV irradiated and at the indicated times the P10 and S100 fractions were isolated and analyzed by immunoblotting with anti-cytochrome $c$ antibody (above). Caspase activity was measured in $\mathrm{S} 100$ from UV-treated cells using DEVD-afc as substrate (below)

S100 fraction was also not observed in S2 cells when apoptosis was induced by overexpression of Hid, Reaper, or Grim (Figure S1).

Previous studies have also suggested that cytochrome $c$ is not required for Drosophila apoptosis, because cells having low levels of cytochrome $c$ still undergo normal apoptosis. ${ }^{22,23}$ We verified these results using RNA-mediated interference (RNAi) to reduce endogenous cytochrome $c$ levels. Drosophila encodes two cytochrome $c$ proteins, DC3, and DC4, and it has been shown that RNAi using $d c 4$ sequences inhibits expression of both genes. ${ }^{22}$ Immunoblot analysis showed a 
significant reduction in cytochrome $c$ protein levels in the $\mathrm{P} 10$ fraction of $\mathrm{S} 2$ cells treated with $d c 4$ dsRNA compared to untreated cells (Figure 2a). Depletion of cytochrome $c$ by RNAi had no effect on apoptosis stimulated by UV or by overexpression of Hid, Rpr, or Grim (Figure S2), and DrICE processing was normal in UV-treated S2 cells in which cytochrome $c$ was depleted (Figure $2 b$ ). In addition, when $\mathrm{S} 100$ from $1 \times 10^{8} \mathrm{~S} 2$ cells that were treated with cytochrome $c$ dsRNA and UV irradiated was mixed with S100 from $2 \times 10^{9}$ untreated cells, the levels of DrICE processing and DEVD-ase activity in the untreated lysate were normal (Figure 2c-e). To verify that the active DrICE detected in the immunoblot in Figure 2c was not from the UV-treated S100 lysate, we analyzed the same amount of UV-treated $S 100$ that was added to untreated lysate in Figure $2 \mathrm{c}$ by immunoblotting and found that DrICE was undetectable in these samples under these conditions (data not shown).

The ability of S100 from UV-irradiated cells to cause caspase activation in $\mathrm{S} 100$ from untreated cells could have been due to either cytosolic proteins (including activated caspases) or to mitochondrial factors (other than cytochrome c) that had been released into the cytosol following UV treatment, or both. To eliminate active caspases from the UV-treated lysate, we performed RNAi to the apical caspase DRONC, followed by UV irradiation. Following DRONC and cytochrome $c$ RNAi, DRONC and cytochrome $c$ protein levels were undetectable by immunoblotting (data not shown) and DrICE was not processed in UV-irradiated cells (Figure 3a). Also, the dronc dsRNA-treated cells did not undergo apoptosis when UV irradiated (data not shown) and neither apical (IETD-ase) nor effector (DEVD-ase) caspase activity were detectable (Figure 3b). However, when $\mathrm{S} 100$ from DRONC RNAi, UV-irradiated cells was mixed with $\mathrm{S} 100$ from untreated cells, DrICE activation was still observed (Figure 4a, lane 3). This indicated that either some other cytosolic factor besides activated caspases or a mitochondrial factor that had been released into the cytosol was responsible for caspase activation. DrICE processing was not observed when untreated $\mathrm{S} 100$ was mixed with $\mathrm{S} 100$ obtained from cells that were not irradiated, regardless of whether cytochrome $c$, DRONC, or both had been depleted (Figure $4 \mathrm{a}$, lanes 2, 4 and 5). a

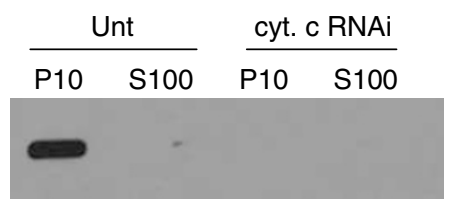

anti-cyt. c

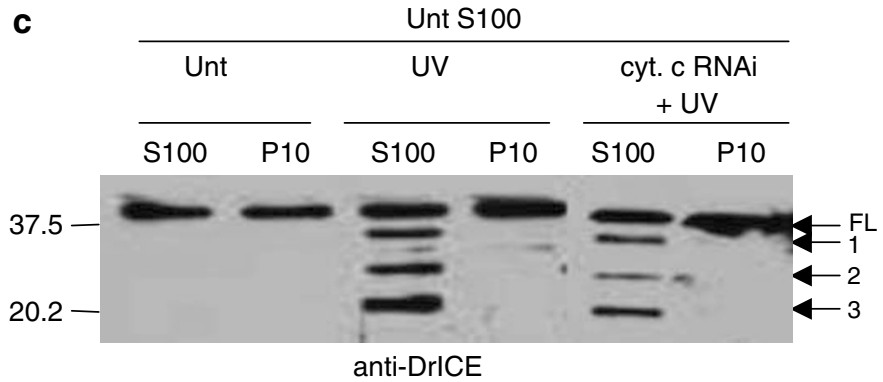

d

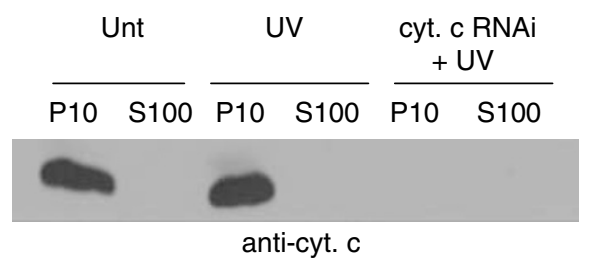

b
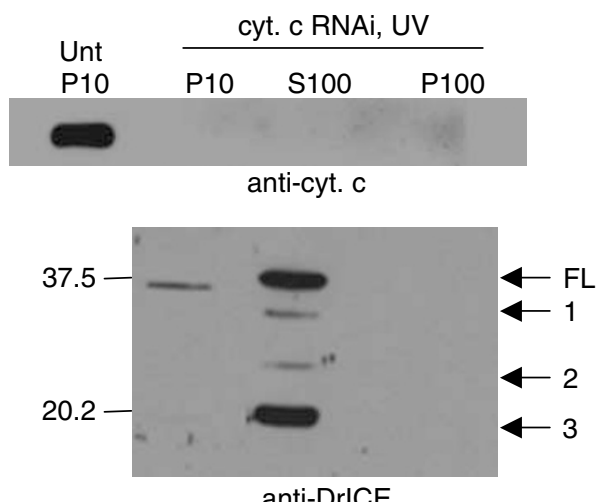

e

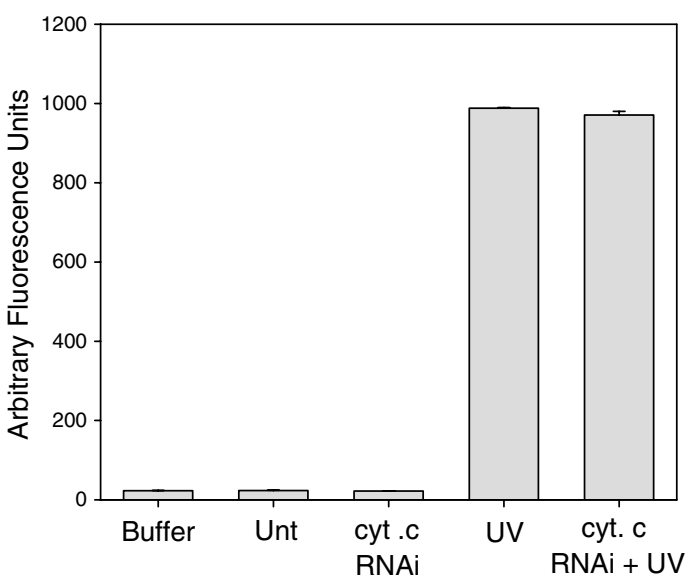

Figure 2 Cytochrome $c$ is not necessary for caspase activation in S2 cells. (a) S2 cells were left untreated (Unt) or were treated with dsRNA corresponding to cytochrome $c$ and $72 \mathrm{~h}$ later the indicated fractions were isolated and analyzed by immunoblotting with anti-cytochrome $c$ antibody. (b) S2 cells were treated with cytochrome $c$ dsRNA and $72 \mathrm{~h}$ later the cells were UV irradiated and analyzed $4 \mathrm{~h}$ later by immunoblotting with anti-DrlCE antibody. Full-length (FL) DrlCE was processed to species 1 (lacking the 28 amino-acid prodomain), 2 (prodomain plus large subunit), and 3 (the p19 large subunit). (c) $\mathrm{S} 100$ from $2 \times 10^{9}$ untreated S2 cells was incubated with P10 or S100 isolated from $1 \times 10^{8} \mathrm{~S} 2$ cells that were untreated, UV irradiated, or UV irradiated and treated with cytochrome $c$ dsRNA. Following the incubation, an immunoblot was performed using anti-DrICE antibody. (d) Anti-cytochrome $c$ immunoblot of the lysates in panel $c$ that were incubated with untreated S100. (e) Measurement of caspase activity (using Ac-DEVD-afc as substrate) in S100 isolated from S2 cells that were treated with cytochrome $c$ dsRNA and UV irradiated 
a

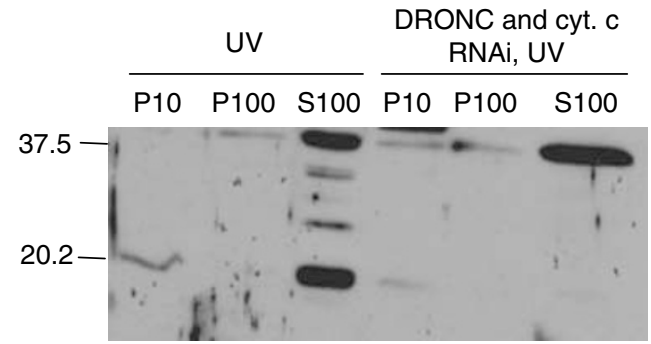

anti-DrICE

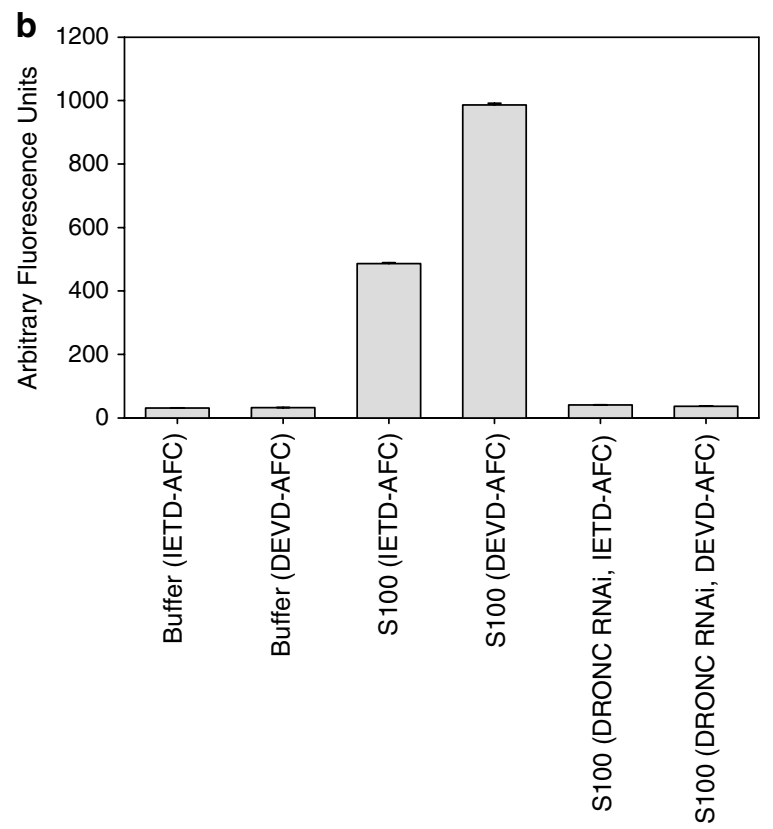

Figure 3 Silencing of the apical caspase DRONC eliminates DrICE processing and caspase activity. (a) S2 cells were treated with dsRNA corresponding to cytochrome $c$ and DRONC and the indicated fractions were isolated and immunoblotted using anti-DriCE antibody. (b) Caspase activity was examined in S2 S100 that was treated with dronc dsRNA using Ac-IETD-afc or Ac-DEVD-afc as substrates

To test whether a mitochondrial factor was responsible, the mitochondrial (P10) fraction was isolated from untreated cells, and mitochondria were lysed by four freeze-thaw cycles. The resulting lysate was then incubated with $\mathrm{S} 100$ fraction from untreated cells. Significant levels of DrICE processing or DEVD-ase activity were not observed in $\mathrm{S} 100$ extract treated with lysed mitochondria (Figure 4b, lanes 9). However, when extract from lysed mitochondria obtained from S2 cells was added to S100 obtained from untreated human 293 cells, caspase activation was observed (Figure $5 b$, sample 5). If the S2 cell mitochondria were not lysed, they did not cause caspase activation in 293 cell S100 (Figure 5b, sample 3). Neither intact nor lysed mitochondria from 293 cells were able to activate caspases in $\mathrm{S} 100$ from untreated S2 cells (Figure 5a, samples 2 and 4). Also, addition of cytochrome $c$ and dATP to S100 from untreated S2 cells did not lead to DrICE processing (Figure 4b, lanes 10 and Figure 5a, sample $8)$, but did cause caspase activation in 293 cell $S 100$ (Figure 5b, sample 8). The cytochrome $c$ that was released from S2 mitochondria by freeze-thawing was required for inducing caspase activation in S100 from 293 cells, since RNAi of cytochrome $c$ eliminated the caspase activating ability of lysed P10 from S2 cells (Figure 5b, sample 7). These results indicate that not only cytochrome $c$ but also other mitochondrial factors are unable to cause caspase activation in $\mathrm{S} 2$ cell $\mathrm{S} 100$.

The difference in requirement for mitochondrial factors in caspase activation between Drosophila and mammalian cells was further illustrated by the observation that when $293 \mathrm{S100}$ was incubated with $\mathrm{S} 100$ isolated from S2 cells that were UV irradiated and treated with the caspase inhibitor zVAD-fmk and cytochrome $c$ dsRNA, caspase activation was not observed, but it was in the S2 S100 (Figure 5a, b, samples 11). The amount of zVAD-fmk used was sufficient to inhibit caspase activity in the S2 S100 (Figure 6, sample 9). To determine if the reason why the $293 \mathrm{~S} 100$ did not show caspase activity when incubated with the treated S2 S100 was due to the lack of mitochondria in the S100, 293 whole-cell lysate (containing both mitochondria and cytosolic factors) was used and the experiment was repeated. Caspases were activated in the 293 whole-cell lysate when it was incubated with the treated S2 S100 (Figure 6, sample 1), indicating that factors in the S2 S100 could only activate caspases in 293 cells if mitochondria were present.

These results indicated that one or more cytosolic factors, which did not include caspases, were responsible for caspase activation in S2 S100. Since Hid, Reaper and Grim are known to interrupt interactions between DIAP1 and caspases, we examined the effect on S2 cell viability when Hid, Rpr, and/or Grim were depleted by RNAi. The RNAi treatment greatly reduced the amount of mRNA for Hid, Rpr, and Grim as measured by RT-PCR (Figure S3). Cells that were treated with Hid, Reaper, or Grim dsRNA were protected from UV-induced apoptosis when compared to S2 cells that were treated with control CAT dsRNA (Figure 7a). S2 cells that were treated with Hid or Grim dsRNA were more protected than cells treated with Rpr dsRNA, while silencing both Hid and Grim enhanced protection. However, the best protection was observed when all three genes were silenced.

When S100 from untreated S2 cells was incubated with S2 S100 that was isolated from cells that were treated with UV, zVAD-fmk, and Hid, Reaper, and Grim dsRNA, caspase activation was significantly reduced compared to control cells not receiving dsRNA (Figure 7b, compare samples 9 and 11). Silencing Hid (sample 13) or Grim (sample 14) individually had more of an effect on caspase activity than silencing $\mathrm{Rpr}$ (sample 15) and silencing Hid and Grim together (sample 17) had more effect than Hid and Rpr (sample 16) or Grim and Rpr (sample 18) (Figure 7b). These results were consistent with the observed protection in Figure $7 \mathrm{a}$.

When 293 whole-cell extract was incubated with S2 S100 isolated from cells that were UV irradiated and treated with zVAD-fmk, caspase activation was observed (Figures 6 and 8 a, sample 3). However, when Hid, Rpr, and Grim were silenced, caspase activity was reduced (Figure 8a, sample 10). When the genes were silenced individually, more of an effect was observed when Reaper or Grim were silenced, while silencing Hid individually had little effect (Figure 8a, samples 4-6). However, silencing all three genes was more 
a

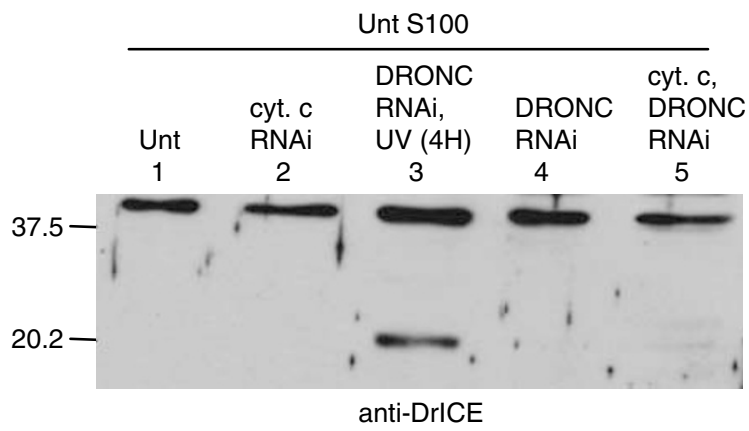

b

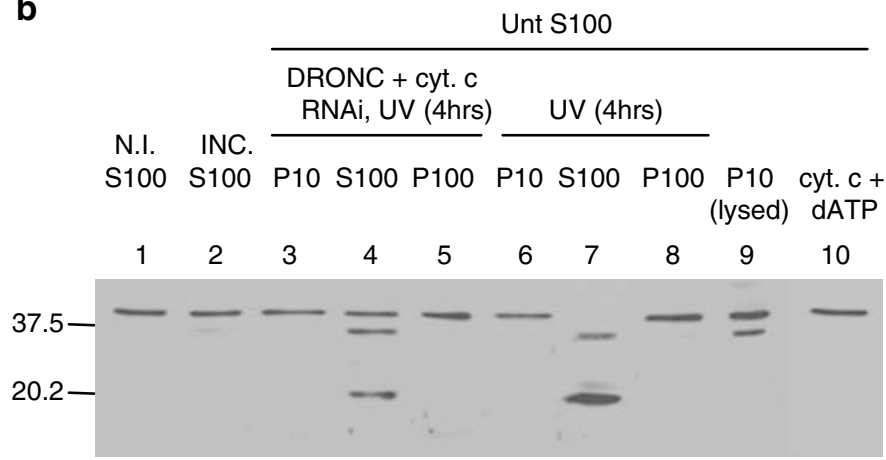

anti-DrICE
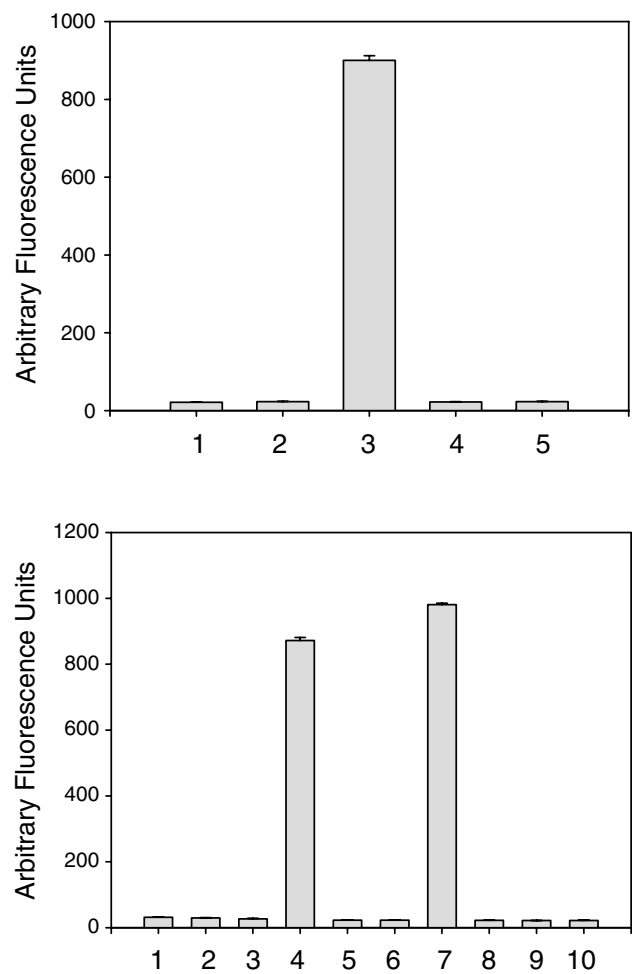

Figure 4 Mitochondrial factors are not able to induce caspase activation in S2 cell lysate. (a) S100 from $2 \times 10^{9}$ untreated S2 cells was incubated with S100 from $1 \times 10^{8} \mathrm{~S} 2$ cells that were untreated, treated with dronc and/or cytochrome $c$ dsRNA, or treated with dronc dsRNA and UV irradiated. An immunoblot was performed for DrICE (left) and caspase activity was determined using Ac-DEVD-afc as substrate (right). (b) DrICE immunoblot (left) and caspase activity assay using DEVD-afc (right) of the following samples: lane 1, nonincubated S100 from untreated S2 cells; lane 2, S100 from untreated S2 cells that was incubated alone; lanes 3-8, S100 from untreated S2 cells that was incubated with the indicated fractions from S2 cells that were UV irradiated or treated with dronc and cytochrome $c$ dsRNA and UV irradiated; lane 9, S100 from untreated cells that was incubated with lysed P10 fraction; lane 10, S100 from untreated cells that was incubated with cytochrome $c$ protein and dATP

effective than silencing only Rpr and Grim (compare samples 9 and 10).

To examine if the S2 S100 caused release of cytochrome $c$ from the 293 cell mitochondria, 293 whole-cell lysates were incubated with treated S2 S100 and then separated into cytosolic and mitochondrial fractions and the cytosolic fractions were immunoblotted for cytochrome $c$ (Figure $8 \mathrm{~b}$ ). 293 cell lysates treated with S100 obtained from S2 cells that were UV-irradiated (lane 5), UV-irradiated and treated with zVAD-fmk (lane 4), or UV-irradiated and treated with dsRNA to Hid, Rpr, and Grim (lane 7) all exhibited cytochrome $c$ release in the cytosol, but when cells were UV irradiated and treated with both zVAD-fmk and dsRNA to Hid, Reaper and Grim, cytochrome $c$ translocation to the cytosol did not occur (lane 6). Thus, either (1) active caspases or (2) Hid, Rpr, and Grim were sufficient to cause cytochrome $c$ release from 293 cell mitochondria, but if caspases were inhibited and Hid, Rpr, and Grim were silenced, cytochrome $c$ release was not observed.

The data in Figure 7 indicate that Hid, Rpr, and Grim (in particular Hid and Grim) are necessary for activation of caspases in S2 S100 extract. To determine if a DIAP1 antagonist was also sufficient to induce caspase activation in S2 cells, we used biotinylated peptides representing either the native or processed amino terminus of the Hid protein. As has been previously shown, ${ }^{26}$ a peptide representing the processed amino terminus of Hid lacking the initiating methionine residue (Hid peptide) bound to DIAP1, but a peptide including the initiating methionine residue (Met-Hid peptide) did not (Figure S4-a). Increasing concentrations of this Hid peptide induced DrICE cleavage and caspase activity in S100 extract from untreated S2 cells, while the Met-Hid peptide did not (Figure 9a, b). The Hid peptide was able to disrupt the interaction between DIAP1 and DRONC, as determined by immunoprecipitation of recombinant proteins, while the MetHid peptide did not (Figure S4-b). However the Hid peptide was unable to disrupt the interaction between DIAP1 and catalytically inactive DRONC (C318S) in which the active site cysteine was mutated to serine (Figure S4-b), supporting previous observations that suggest that the binding contacts are different between DIAP1 and active DRONC versus inactive DRONC. ${ }^{27,28}$ The Hid peptide was also able to bind to endogenous DIAP1 when it was mixed with S2 cell lysate (Figure S4-c).

To determine if inhibiting the interaction between DIAP1 and DRONC was sufficient to induce apoptosis, we transfected the Hid peptide or the control Met-Hid peptide into S2 cells. The transfected Hid peptide formed a complex with endogenous DIAP1 (Figure S4-c, lane 8). Approximately $60 \%$ of the S2 cells transfected with the Hid peptide died by 
a

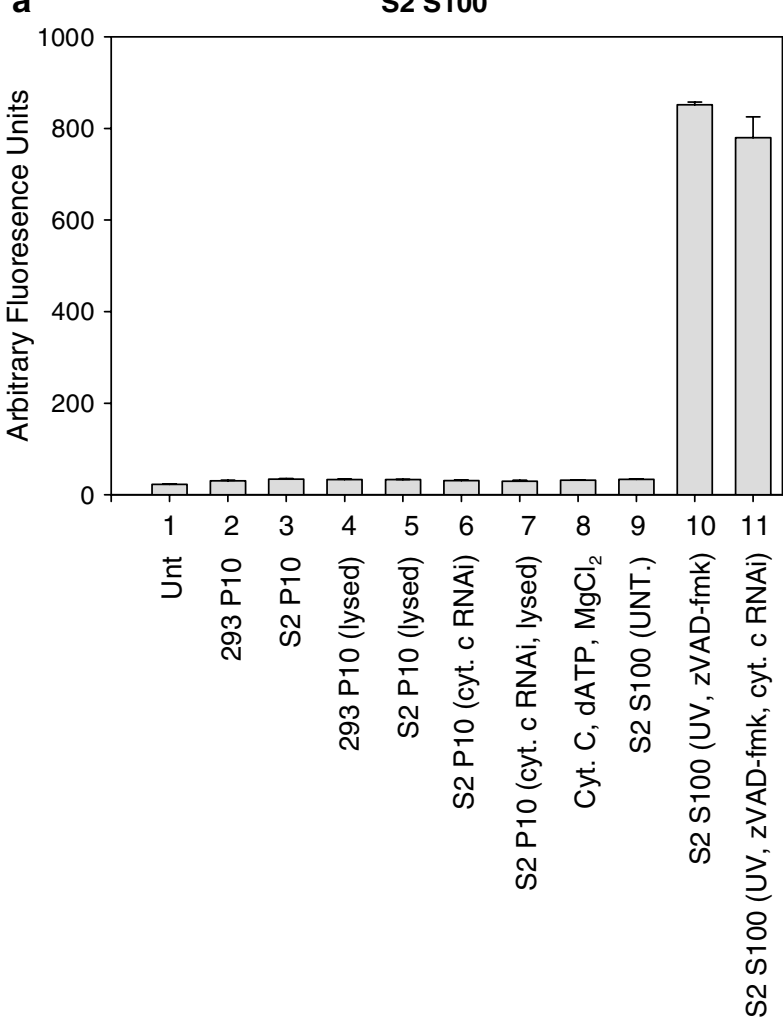

b $293 S 100$

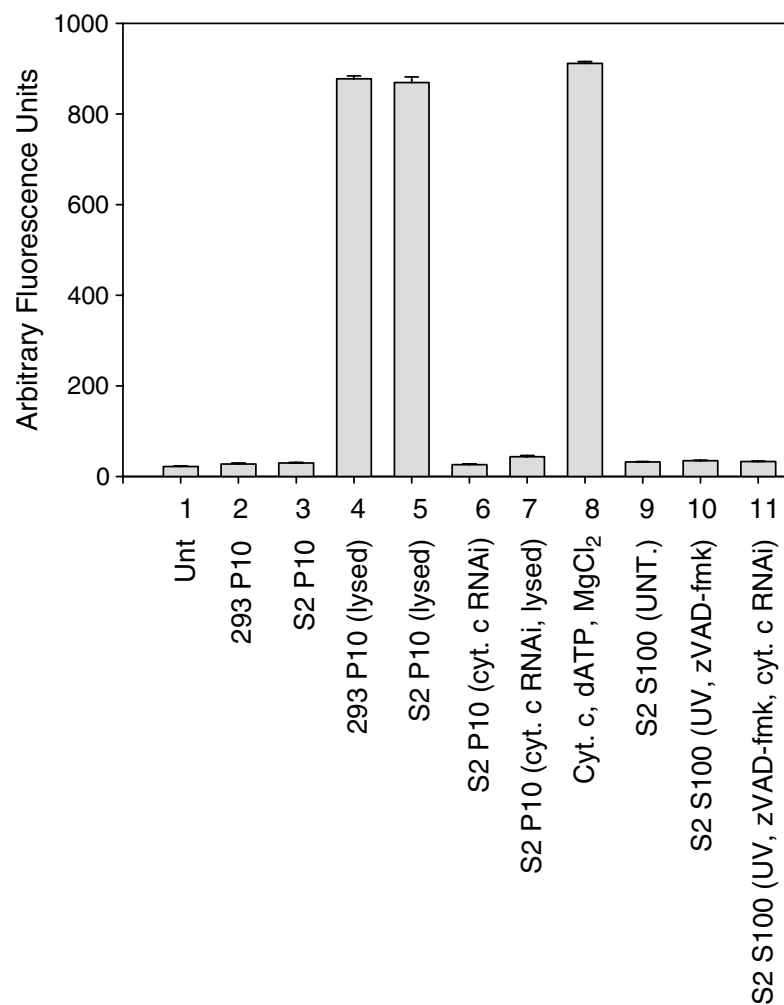

Figure 5 Lysed S2 cell mitochondria are capable of inducing caspase activation in S100 obtained from human cells but not in S100 from Drosophila cells. S100 lysate obtained from untreated $2 \times 10^{9}$ Drosophila S2 (a) or $5 \times 10^{6}$ human 293 (b) cells was incubated with either S2 or 293 P10, purified cytochrome $c$, or S100 from $1 \times 10^{8}$ UV-treated S2 cells treated with the caspase inhibitor ZVAD-fmk and caspase activity was determined using DEVD-afc as substrate

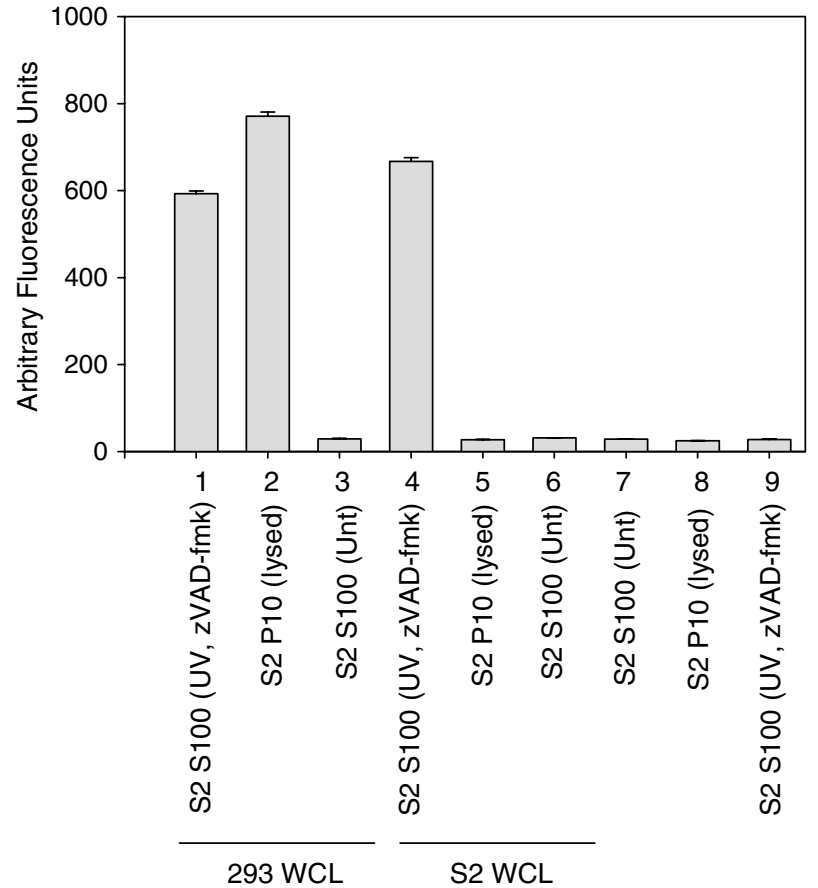

Figure $6 \mathrm{~S} 100$ from UV-treated S2 cells treated with caspase inhibitor is able to activate caspases in 293 or S2 whole-cell extract. S100 isolated from $1 \times 10^{8} \mathrm{~S} 2$ cells that were UV irradiated and treated with z-VAD-fmk was incubated alone (samples 7-9) or with 293 or S2 whole-cell lysate (WCL) and caspase activity was determined using DEVD-afc as substrate apoptosis, as determined by observing cell morphology (data not shown) and by the fact that the cell death was inhibited by z-VAD-fmk, while S2 cells transfected with the Met-Hid peptide did not undergo apoptosis (Figure 10a). Transfection of Hid or Met-Hid peptides into human 293 cells had no affect on cell viability (Figure 10b). These results provide strong evidence that interruption of the DIAP1-DRONC interaction is sufficient to induce caspase activation and apoptosis in S2 cells.

The data presented so far indicate that mitochondrial factors are not required for caspase activation in S2 cells, but do not rule out a role for these factors in enhancing or accelerating caspase activation. To determine if mitochondria or mitochondrial factors could play a role in enhancing or accelerating caspase activation in vitro, S100 lysate that was isolated from UV-irradiated and zVAD-fmk treated S2 cells was incubated with S2 P10 fraction for $1 \mathrm{~h}$ prior to incubation with untreated S2 S100, and at various time points caspase activity was measured. The kinetics of caspase activation in the untreated S100 was not altered by the addition of either intact or lysed mitochondria obtained from either untreated or UV-irradiated S2 cells, indicating that mitochondria or mitochondrial factors do not play a role in caspase activation in this system (Figure 11).

Next, the efficiency of caspase activation by the Hid peptide was compared to full-length Reaper and Hid proteins. Fulllength Hid and Reaper proteins that contained either a His tag on the $\mathrm{C}$-terminus of the protein or a glutathione- $S$-transferase 


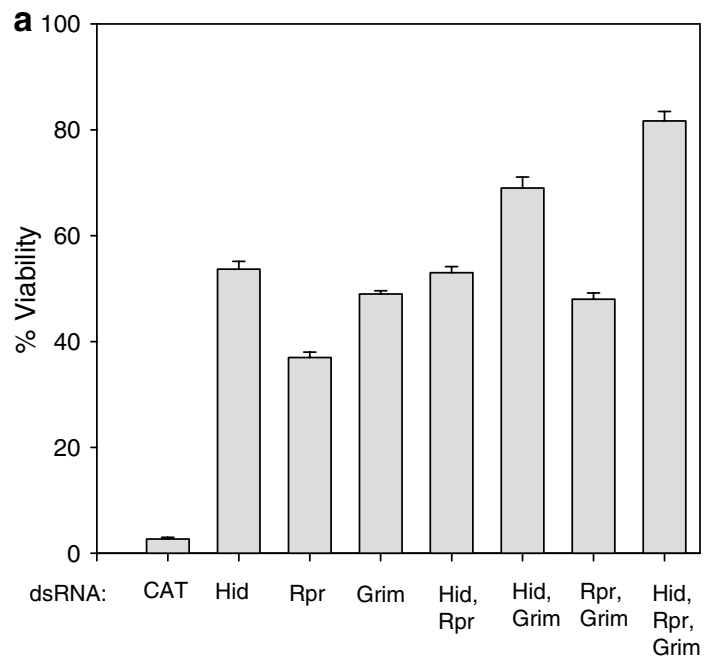

UV

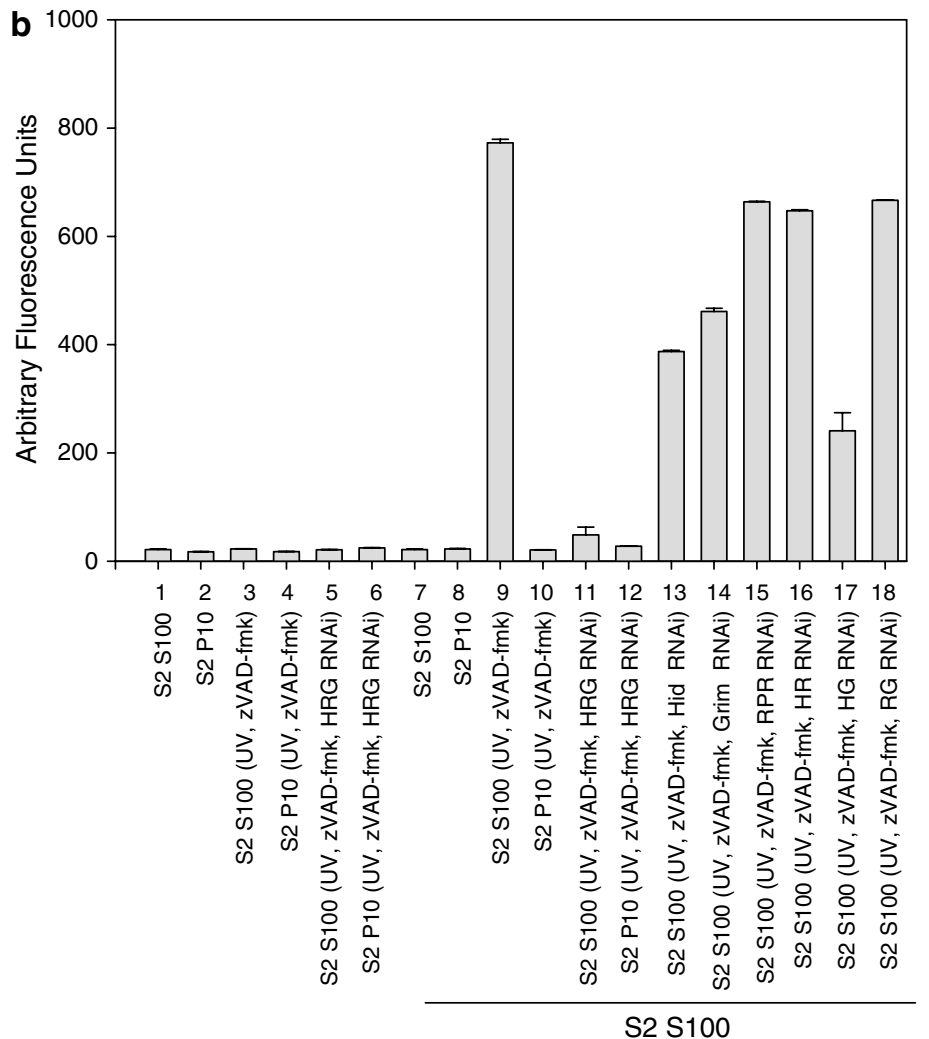

Figure 7 Silencing of Hid, Rpr, and/or Grim protects S2 cells against UV-induced apoptosis and inhibits caspase activation in S100. (a) S2 cells were treated with dsRNA corresponding to CAT (negative control), Hid, Rpr, Grim or combinations of Hid, Rpr and Grim. At $48 \mathrm{~h}$ after dsRNA addition, the cells were UV irradiated and $24 \mathrm{~h}$ later cell viability was determined. (b) S100 or P10 from $1 \times 10^{8}$ S2 cells that were UV irradiated and treated with dsRNA corresponding to Hid, Rpr, and Grim was incubated alone (samples 1-6) or with S100 from $2 \times 10^{9}$ untreated S2 cells (lanes 7-18). Caspase activity was determined using DEVD-afc as substrate

(GST) tag on the N-terminus (which would be expected to block the IAP binding motifs) were expressed in bacteria. The Hid peptide and the Reaper and Hid fusion proteins were then compared in their ability to induce caspase activation in vitro. Increasing equimolar concentrations of the Hid peptide, fulllength Hid (His- or GST-tagged), Reaper (His- or GST-tagged) or GST were incubated with untreated S2 S100 and caspase activity was measured. At the lowest concentration used, $0.25 \mu \mathrm{M}$, caspase activation was greatest for full-length HidHis, followed by Reaper-His, and finally the Hid peptide (Figure 12a). However, at the next highest concentration $(0.6 \mu \mathrm{M})$, and at all higher concentrations, the Hid peptide was as efficient as Reaper-His at inducing caspase activation (Figure 12b-f), and at $100 \mu \mathrm{M}$ the Hid peptide was as efficient as both Reaper-His and Hid-His (Figure 12f).

The observation that full-length Reaper and Hid were more efficient at inducing caspase activation at lower concentrations than the Hid peptide raised the possibility that other domains in Reaper and Hid besides the N-terminal IAP binding domain were contributing to caspase activation, although the IAP binding domain was clearly required for this activity since the GST fusion proteins had little or no activity. Since Reaper has been shown to localize to mitochondria by virtue of its $\mathrm{GH} 3$ domain, ${ }^{25}$ either intact or lysed mitochondria were also added to the reactions to see if they could enhance or accelerate caspase activity. When P10 that was isolated from $S 2$ cells that were UV-irradiated was added, there was no apparent increase or enhancement of caspase activity triggered by Hid-His or Reaper-His (Figure 12). P10 that was isolated from untreated $S 2$ cells also had no effect on caspase activation, and P10 that was subjected to freezethawing to lyse the mitochondria after being isolated from either untreated or UV-irradiated S2 cells yielded the same results (data not shown). In addition, the Met-HID peptide showed no caspase-activating ability at any of the concentrations tested (data not shown).

An alternative explanation for why the full-length Reaper and Hid proteins caused caspase activation more efficiently than the Hid peptide is that the full-length proteins caused destabilization of DIAP1 in the S100 lysate. To test this, we incubated the full-length proteins or the Hid peptide with $\mathrm{S100}$ and then analyzed the levels of endogenous DIAP1 in the $\mathrm{S} 100$ by immunoblotting. Incubation with either Hid-His or the Reaper-His resulted in decreased levels of DIAP1, while incubation with the Hid peptide did not (Figure S5). Thus, it appears that the full-length proteins were able to induce degradation of DIAP1 in the S100 lysate, which contributed to their ability to cause caspase activation.

\section{Discussion}

In mammalian cells, release of cytochrome $c$ is an essential step in mediating caspase activation following stimulation of 


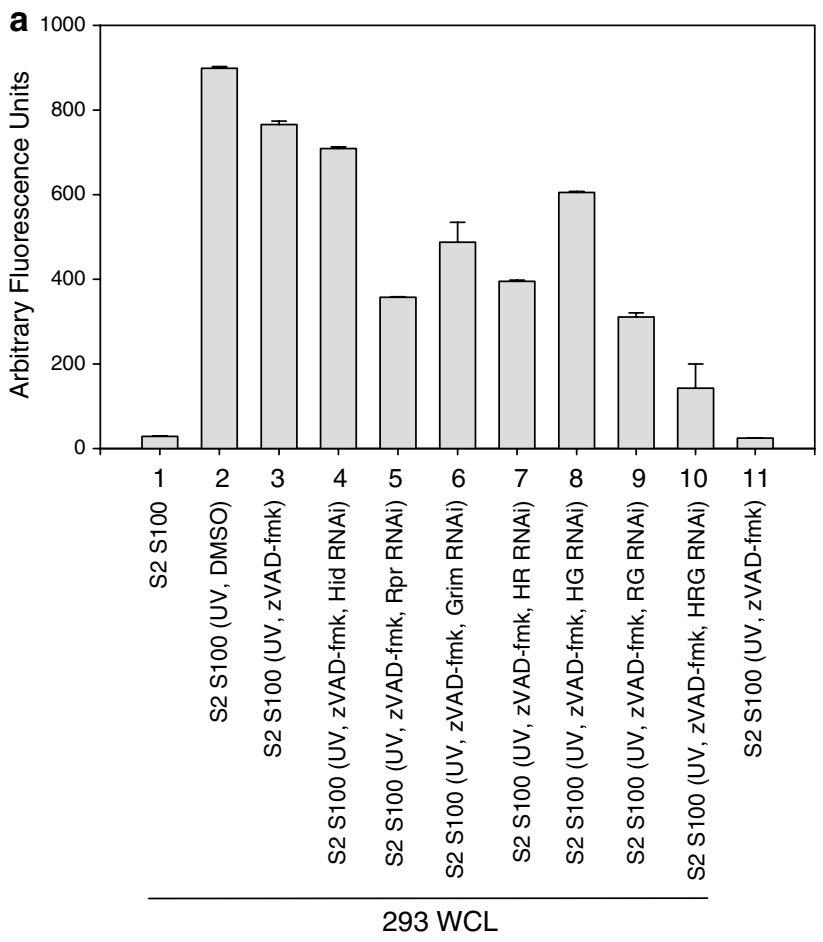

b

\begin{tabular}{|c|c|c|c|c|c|c|c|}
\hline \multicolumn{3}{|c|}{ S2 WCL } & \multicolumn{5}{|c|}{293 WCL } \\
\hline 1 & 2 & 3 & 4 & 5 & 6 & 7 & 8 \\
\hline
\end{tabular}

Figure 8 Silencing Hid, Rpr and Grim reduces the ability of S2 S100 to cause caspase activation in 293 whole-cell extract. (a) 293 whole-cell lysate (WCL) was incubated with $\mathrm{S} 100$ isolated from S2 cells that were UV irradiated and treated with zVAD-fmk and dsRNA corresponding to Hid, Reaper, or Grim. Caspase activity was determined using DEVD-afc as substrate. (b) Cytochrome c immunoblot of cytosolic fractions isolated from S2 or 293 WCL that had been incubated with $\mathrm{S} 100$ from S2 cells that were UV irradiated and treated with ZVADfmk (lanes 1 and 4), UV irradiated (lanes 2 and 5), UV irradiated and treated with zVAD-fmk and Hid, Rpr and Grim dsRNA (lanes 3 and 6), UV irradiated and treated with Hid, Rpr and Grim dsRNA (lane 7), or untreated (lane 8)

the intrinsic apoptosis pathway. However, most previous studies have found that cytochrome $c$ is not released during apoptosis in Drosophila S2 cells, and depletion of cytochrome $c$ does not affect apoptosis in Drosophila cells and larvae. ${ }^{21-24}$ Previous studies have also shown that mitochondria do not lose their membrane potential during the early stages of apoptosis in Drosophila. ${ }^{22,24}$ Consistent with these reports, we also did not observe release of cytochrome $c$ in apoptotic S2 cells following UV irradiation or overexpression of Hid, Reaper, or Grim. When we treated S2 cells with cytochrome $c$ dsRNA to suppress expression of cytochrome $c$ protein and then induced apoptosis, the S2 cells showed no increased resistance to apoptosis and caspase activation was unaffected. It was previously shown that cytochrome $c$ failed to induce caspase activation in insect cell extracts ${ }^{21}$ and we also found that addition of cytochrome $c$ to $\mathbf{S 1 0 0}$ did not induce DrICE activation. These data along with ours support the
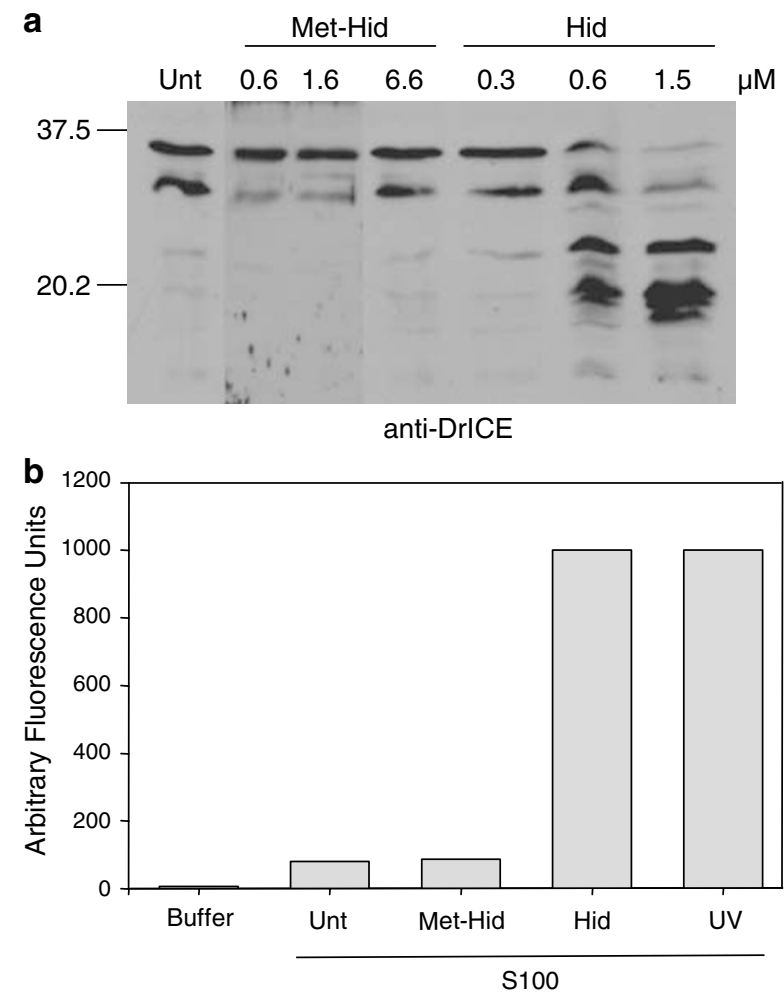

Figure 9 A peptide consisting of the Hid amino terminus (lacking the initiating methionine) is sufficient to induce caspase activation in S100 from untreated S2 cells. (a) S100 from untreated S2 cells was incubated alone (Unt) or with increasing concentrations of Hid or Met-Hid peptide, followed by immunoblotting for DrICE. (b) S100 from untreated S2 cells was incubated alone (Unt) or with Met-Hid peptide $(1.6 \mu \mathrm{M})$ or Hid peptide $(1.5 \mu \mathrm{M})$, and caspase activity assay was performed using DEVD-afc as the substrate. UV, S100 from untreated cells was incubated with S100 from S2 cells that had been UV irradiated. Buffer, caspase assay performed using only buffer and DEVD-afc

fact that cytochrome $c$ is not required for apoptosis in Drosophila.

Although the requirement for cytochrome $c$ has been examined previously, this is the first report that we are aware of which has examined whether other mitochondrial factors can induce caspase activation in Drosophila cells. In mammals, there is accumulating evidence that the mitochondria are an essential component during intrinsic apoptosis by releasing apoptogenic factors such as cytochrome $c,{ }^{9} \mathrm{AIF},{ }^{29}$ Smac/Diablo, ${ }^{30,31}$ EndoG, ${ }^{32}$ or $\mathrm{HtrA} 2 / \mathrm{Omi}^{33}$ from the intermembrane space into the cytoplasm. To determine if there is any involvement of other mitochondrial factors besides cytochrome $c$ for caspase activation in Drosophila, we isolated the mitochondrial and cytosolic fractions from S2 cells that were either normal or apoptotic. None of the P10 fractions were able to induce caspase activation in $\mathrm{S} 100$ from normal cells, even when the mitochondria were lysed by freeze-thawing to release their contents. These lysed mitochondria from S2 cells were able to induce caspase activation in $\mathbf{S} 100$ from mammalian 293 cells, and cytochrome $c$ appeared to be responsible for this activation. In contrast, cytosolic (S100) fractions isolated from apoptotic S2 cells were able to induce caspase activation in $\mathrm{S} 100$ isolated from 
a

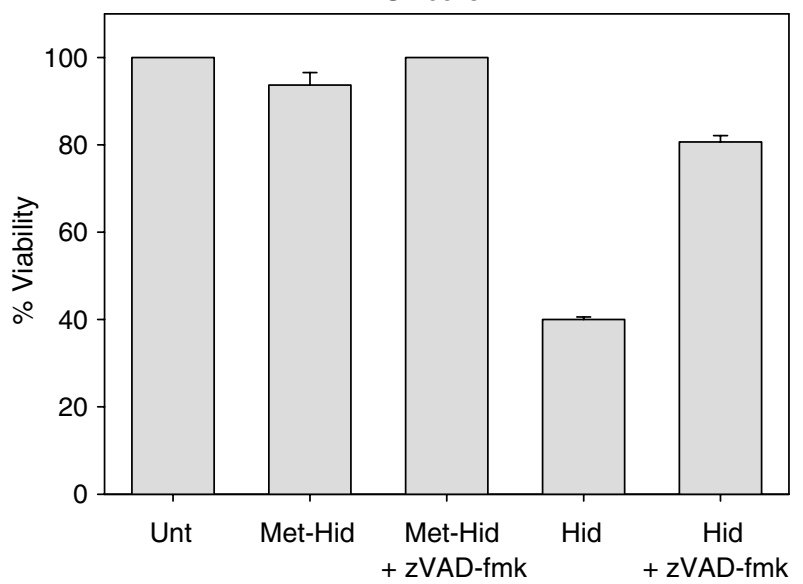

b

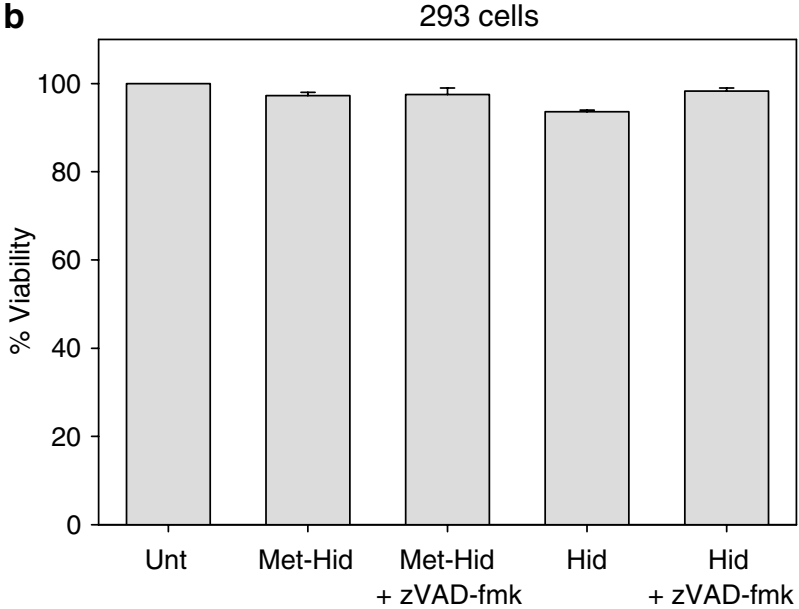

Figure 10 The Hid peptide induces apoptosis when transfected into $\mathrm{S} 2$ cells. S2 cells (a) or 293 cells (b) were cotransfected with Hid or Met-Hid peptides and a plasmid expressing eGFP. Cells were treated with zVAD-fmk or carrier control and $48 \mathrm{~h}$ later viability was determined. Unt, untreated cells

untreated S2 cells, even when caspase activity was inhibited in the apoptotic $\mathrm{S} 100$. This indicated that one or more factors found in the cytosol, which were not caspases, were able to cause caspase activation in normal S100. By using RNAi, we were able to show that Hid, Rpr, and Grim are necessary in an overlapping manner for the caspase-activating activity found in the cytosol of S2 cells.

Using a peptide consisting of amino acids 2-11 of HID, which is able to disrupt DIAP1 binding to DRONC in vitro, we showed that displacement of DIAP1 from DRONC is also sufficient for activation of caspases in S2 S100. This Hid peptide also induced apoptosis when it was introduced into S2 cells. Thus, our results provide the strongest evidence to date that all that is required for caspase activation in S2 cells is interruption of the binding between DIAP1 and DRONC, and that mitochondrial factors do not play a role in Drosophila caspase activation. The possibility remains, however, that mitochondria themselves may play a role in localizing components of the apoptosome in intact cells, as immunofluorescence assays have indicated that a portion of the DRONC and DrICE proteins in Drosophila BG2 cells are

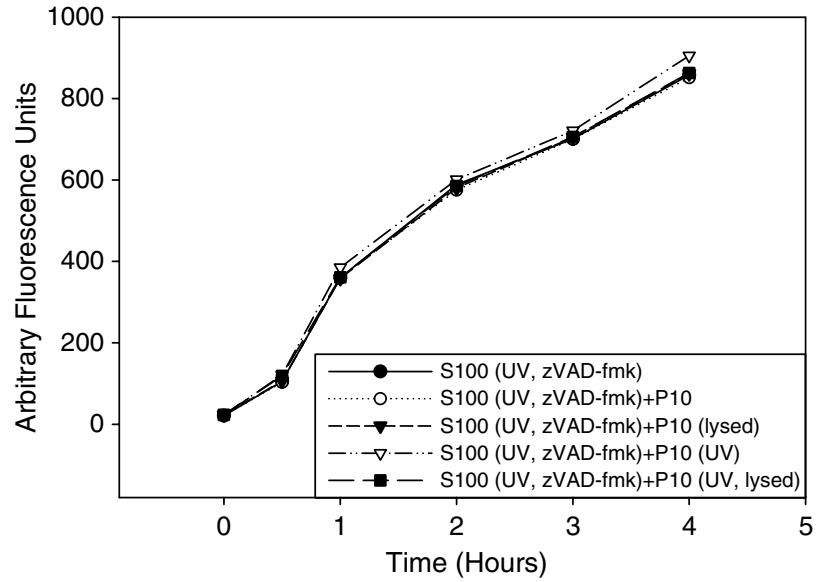

Figure 11 Intact mitochondria or mitochondrial factors do not enhance or accelerate caspase activation in S2 cell lysate. P10 from untreated or UVirradiated S2 cells were isolated and either lysed or left intact and incubated with S2 S100 that was isolated from UV-irradiated and ZVAD-fmk treated S2 cells for $1 \mathrm{~h}$ followed by the addition of untreated S2 S100. Caspase activity was measured using Ac-DEVD-afc as substrate

localized on the outer surface of mitochondria. ${ }^{24}$ In agreement with this, we observed DrICE protein in both the $\mathrm{S} 100$ and $\mathrm{P} 10$ fractions. However, addition of intact mitochondria did not have any stimulatory effect on caspase activation in our in vitro assay, so at least in vitro, there may be sufficient DARK, DRONC, and DrICE in S100 to become activated without the need for mitochondria to bring the proteins together.

Full-length, C-terminally tagged Hid and Reaper proteins caused caspase activation more efficiently than the Hid peptide at the lowest concentration tested, although the Hid peptide was as efficient as Reaper at higher concentrations. The reason why the full-length proteins were more efficient at inducing caspase activation appears to be due to the ability of the full-length proteins to cause DIAP1 destabilization in the S100 lysate, and not to interactions of the full-length proteins with mitochondria or mitochondrial factors. The IAP binding motif was required, since the N-terminally GST-tagged versions had little or no activity in the assay. Removal of the initiating methionine residue from the recombinant proteins, which would be necessary to uncover the IAP binding domain, presumably occurred during expression in the bacteria, as this routinely occurs with bacterially expressed proteins containing alanine in the second position. ${ }^{34}$ In addition to the IAP binding domain, Reaper has been shown to contain a second motif, called the GH3 domain, that has been reported to be required for DIAP1 degradation, as well as to target Reaper to S2 mitochondria and cause cytochrome $c$ release in mammalian mitochondria. ${ }^{25}$ The $\mathrm{C}$-terminus of $\mathrm{Hid}$ is also capable of mediating mitochondrial localization. ${ }^{25}$ If these domains of Reaper and Hid were acting by interacting with low level contaminating mitochondrial membranes in the $S 100$, then addition of higher levels of P10 lysate would be expected to cause even higher levels of caspase activation. However, addition of either intact or lysed mitochondria had no effect in our assay, in either the presence or absence of full-length Reaper or Hid. Incubation with Reaper-His or Hid-His did, however, result in decreased levels of DIAP1. This result 


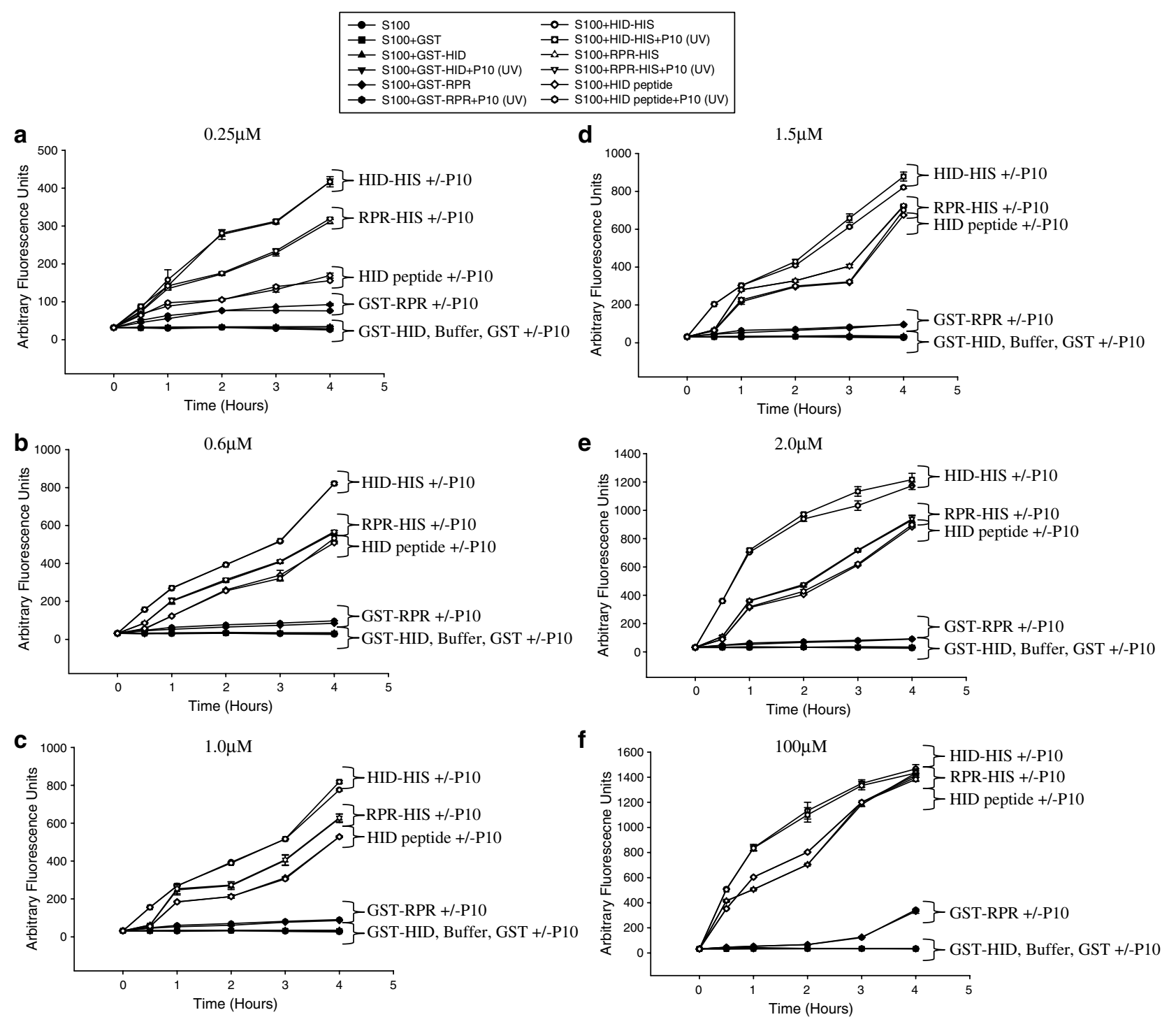

Figure 12 Full-length Reaper and Hid proteins are more efficient at activating caspases compared to the Hid peptide. Recombinant full-length Hid-His, GST-Hid, Reaper-His, GST-Reaper or GST alone were incubated with S2 S100, with or without P10 and at various times after incubation caspase activity was measured using Ac-DEVD-afc as substrate

suggests that proteasome-mediated degradation of DIAP1, which has been shown to be triggered by interaction with Reaper, Hid, or Grim, ${ }^{35,36}$ was induced by the addition of Reaper-His or Hid-His to the $\mathrm{S100}$ lysate. This explains why the full-length proteins were more efficient at inducing caspase activation than the Hid peptide.

S100 extract from apoptotic S2 cells was also able to induce caspase activation in 293 whole-cell lysate. This activity appeared to be due to both caspases and Hid, Rpr, and Grim, as inhibition of both of these activities was required to inhibit the caspase activating activity. The observation that apoptotic S2 S100 was not able to induce caspase activation in the absence of mitochondria argues that in 293 S100, Hid, Reaper, and Grim or caspases target the mitochondria and lead to a release of cytochrome $c$. However, in S2 cells, mitochondria are not required and Hid, Reaper, and Grim appear to target the DIAP1-DRONC complex and remove DIAP1 inhibition of DRONC.

In conclusion, based on these results as well as previous studies, it appears that mitochondrial factors do not play a significant role in Drosophila caspase activation. In S2 cells, DRONC undergoes continuous autoprocessing and this is dependent on DARK. ${ }^{28}$ DIAP1 binds to DRONC and causes ubiquitination and degradation of autoprocessed DRONC. ${ }^{37}$ This interaction is required to prevent the cells from undergoing apoptosis. When DIAP1 levels are reduced or when binding of DIAP1 and DRONC is antagonized by Hid, Rpr, or Grim, apoptosis proceeds spontaneously without the need for mitochondrial factors. The possibility remains that in intact Drosophila cells, mitochondria play a role in localizing apoptosome-like complexes, but this does not seem to be required in vitro. It also remains possible that mitochondrial factors play other roles in Drosophila apoptosis, such as 
inducing DNA cleavage, or have a role in inducing noncaspase mediated cell death. However, our results indicate that factors resident in mitochondria do not play an important role in triggering caspase activation in Drosophila, unlike in mammalian cells. Thus, the reason why Reaper and Hid localize to mitochondria in intact S2 cells may simply be to bring them in close proximity with apoptosome complexes assembled at the mitochondria surface, and not to cause release of mitochondrial factors.

\section{Materials and Methods}

\section{Cell culture}

Drosophila S2 cells were maintained in Schneider's medium supplemented with $10 \%$ fetal bovine serum (FBS). Human 293 cells were maintained in Dulbecco's modified Eagle's medium supplemented with 10\% FBS, $10 \%$ Optimem and 1\% Glutamax. All cell culture media and supplements were purchased from Invitrogen.

\section{Cell fractionation}

Cell fractionation was performed essentially as described previously (Dorstyn et al., 2002). S2 cells $\left(2 \times 10^{9}\right.$ untreated or $1 \times 10^{8}$ treated) or $5 \times 10^{6} 293$ cells were harvested by centrifugation at $400 \times g$ for 5 min. Cell pellets were resuspended in $1 \mathrm{ml}$ of Caspase buffer $A(20 \mathrm{mM}$ HEPES · $\mathrm{KOH}, \mathrm{pH} 7.5,50 \mathrm{mM} \mathrm{KCl}, 1.5 \mathrm{mM} \mathrm{MgCl}$, $1 \mathrm{mM}$ EDTA, $1 \mathrm{mM}$ EGTA, $1 \mathrm{mM}$ DTT in $250 \mathrm{mM}$ sucrose supplemented with protease inhibitor cocktail). Cells were homogenized using a Dounce homogenizer by 250 strokes with a tight fitting pestle, and homogenates were centrifuged at $500 \times g$ for $10 \mathrm{~min}$ at $4^{\circ} \mathrm{C}$. The supernatant was centrifuged at $10000 \times g$ for $15 \mathrm{~min}$ at $4^{\circ} \mathrm{C}$ and the mitochondrial pellet (P10) was resuspended in $1 \mathrm{ml}$ Caspase Buffer $A$ and stored at $-20^{\circ} \mathrm{C}$. The supernatant was further centrifuged at $100000 \times g$ for $30 \mathrm{~min}$ at $4^{\circ} \mathrm{C}$. The resulting pellet (P100) was resuspended in $500 \mu$ l of Caspase Buffer $A$ and stored at $-20^{\circ} \mathrm{C}$. Glycerol $(10 \%)$ was added to the resulting supernatant (S100) and the lysate was stored at $-80^{\circ} \mathrm{C}$.

\section{Recombinant protein and peptide preparation}

GST, GST-DIAP1 (N-terminally tagged), DRONC-His ${ }_{6}$ (C-terminally tagged), DRONC (C318S)-His ${ }_{6}$ (C-terminally tagged), GST-Reaper (Nterminally tagged), GST-Hid (N-terminally tagged), Hid-His 6 (C-terminally tagged), and Reaper-His 6 (C-terminally tagged) were expressed in BL21pLysS(DE)3 Eschericia coli (Stratagene). Cultures were grown at room temperature to $\mathrm{OD}_{600}=0.4$, at which time they were induced with $0.1 \mathrm{M} \mathrm{IPTG}$ for $1 \mathrm{~h}$, except for Hid-His and GST-Hid, which were grown overnight at $8^{\circ} \mathrm{C}$ to $\mathrm{OD}_{600}=0.4$, and induced with $0.2 \mathrm{M} \mathrm{IPTG}$. The bacteria were sonicated in lysis buffer A (200 mM Tris-Cl pH 8.0, 0.4 M ammonium sulfate, $10 \mathrm{mM} \mathrm{MgCl}_{2}, 10 \%$ glycerol, and protease inhibitor cocktail (Roche) and purified using either glutathione-sepharose-conjugated beads for GSTDIAP1 or with Talon Metal Affinity Resin (Clontech) for the His ${ }_{6}$ tagged caspases, according to the manufacturer's instructions. The Met-Hid (MAVPFYLPEGGK-biotin) and Hid (AVPFYLPEGGK-biotin) peptides were synthesized by Sigma-Genosys and were previously described. ${ }^{38}$

\section{Coimmunoprecipitations}

To examine DIAP1 interaction with the Hid peptide, recombinant GSTDIAP1 $(0.5 \mu \mathrm{M})$ was incubated with increasing concentrations of either the
Hid peptide or the Met-Hid peptide at $30^{\circ} \mathrm{C}$ for $1 \mathrm{~h}$. After incubation, the reaction was added to $50 \mu \mathrm{l}$ of streptavidin beads and rocked overnight at $4{ }^{\circ} \mathrm{C}$. The beads were washed three times with NP-40 lysis buffer $(50 \mathrm{mM}$ Tris- $\mathrm{HCl}, \mathrm{pH} 8.0,150 \mathrm{mM} \mathrm{NaCl}, 1 \% \mathrm{NP}-40,1 \mathrm{mM}$ dithiothreitol, $1 \mathrm{mM}$ phenylmethyl sulfonyl fluoride) and bound protein was removed from the streptavidin beads by boiling the samples in Laemmli buffer for $5 \mathrm{~min}$. Proteins were analyzed by immunoblotting using anti-DIAP1 monoclonal antibody at 1:100 and anti-mouse IgG-HRP (horseradish peroxidase) antibody at $1: 4000$.

To determine if the Hid peptide could displace DIAP1 from DRONC, $0.5 \mu \mathrm{g}$ each of GST-DIAP1 and either wild-type DRONC-His ${ }_{6}$ or catalytically inactive DRONC-His ${ }_{6}$ (C318S) were mixed together in a total volume of $40 \mu \mathrm{l}$ of Caspase Buffer $\mathrm{A}$ and incubated for $1 \mathrm{~h}$ at $30^{\circ} \mathrm{C}$. Hid or Met-Hid peptide was then added to the reaction and allowed to incubate for $4 \mathrm{~h}$ at $30^{\circ} \mathrm{C}$. The reactions were then added to $50 \mu$ l of protein $\mathrm{G}$ beads (Sigma) that had been preincubated with anti-DRONC antibody (1:100) (obtained from Bruce Hay, California Institute of Technology) and rocked overnight at $4^{\circ} \mathrm{C}$. The beads were washed three times with Caspase Buffer $A$ and bound protein was removed from the protein $G$ beads by boiling the samples in Laemmli buffer for $5 \mathrm{~min}$. SDS-PAGE and immunoblotting was then performed using anti-DIAP1 monoclonal antibody (obtained from Bruce Hay) at 1:100, anti-mouse IgG antibody conjugated with HRP at $1: 3000$ and Supersignal West Pico Chemiluminesent Substrate (Pierce).

To determine if endogenous DIAP1 could bind to Hid peptide, $50 \mu \mathrm{g}$ of Hid peptide was added to $100 \mu$ l of streptavidin-conjugated beads (Sigma) in NP-40 lysis buffer and rocked for $1 \mathrm{~h}$ at $4^{\circ} \mathrm{C}$ to allow the Hid peptide to bind to the beads. The beads were washed two times with NP-40 lysis buffer. $1.4 \times 10^{8} \mathrm{~S} 2$ cells were harvested in $600 \mu \mathrm{l}$ of NP-40 lysis buffer and lysed for $30 \mathrm{~min}$ at $4^{\circ} \mathrm{C}$. After $30 \mathrm{~min}$, the lysates were spun at $21000 \times g$ at $4^{\circ} \mathrm{C}$ for $5 \mathrm{~min}$. The lysates were either added to the Hid peptide-bound streptavidin beads and rocked overnight at $4^{\circ} \mathrm{C}$ or incubated with the Hid peptide for $1 \mathrm{~h}$ at $30^{\circ} \mathrm{C}$ and then added to $100 \mu \mathrm{l}$ of streptavidin beads and rocked overnight at $4^{\circ} \mathrm{C}$. The beads were washed three times with NP-40 lysis buffer and bound protein was removed from the beads by boiling in Laemmli buffer for $5 \mathrm{~min}$. Proteins were analyzed by immunoblotting using anti-DIAP1 monoclonal antibody at $1: 100$ and anti-mouse IgG-HRP antibody at $1: 4000$. The experiment was also performed using S2 S100 instead of whole-cell lysate.

Alternatively, S2 cells $\left(6 \times 10^{6}\right.$ cells per well) were transfected with $3 \mu \mathrm{g}$ of Hid peptide. After $8 \mathrm{~h}$, cells were harvested in $200 \mu \mathrm{l} /$ well of NP-40 lysis buffer. Three wells were combined and lysed for $30 \mathrm{~min}$ at $4^{\circ} \mathrm{C}$. After $30 \mathrm{~min}$ the lysates were spun at $21000 \times \mathrm{g}$ at $4^{\circ} \mathrm{C}$ for $5 \mathrm{~min}$. The supernatant was then added to $50 \mu \mathrm{l}$ of streptavidin beads and rocked overnight at $4{ }^{\circ} \mathrm{C}$. The beads were washed three times with NP-40 lysis buffer and bound protein was removed from the streptavidin beads by boiling the samples in Laemmli buffer for $5 \mathrm{~min}$. Proteins were analyzed by immunoblotting using anti-DIAP1 monoclonal antibody at $1: 100$ and antimouse IgG-HRP antibody at $1: 4000$.

\section{RNAi procedure}

The RNAi method used was essentially the same as that previously described. ${ }^{37}$ S2 cells were placed in TC100 medium (Invitrogen) without serum and double-stranded RNA (dsRNA) corresponding in sequence to the entire ORF sequence of the gene being silenced was added directly to the medium at a concentration of $80-120 \mu \mathrm{g} / \mathrm{ml}$ followed by vigorous shaking. The cells were incubated for $5.5 \mathrm{~h}$ at $25^{\circ} \mathrm{C}$ at which time FBS was added to a final concentration of $10 \%$. Cells treated with cytochrome $c$ dsRNA were supplemented with $50 \mu \mathrm{g} / \mathrm{ml}$ uridine and $110 \mu \mathrm{g} / \mathrm{ml}$ pyruvate 
as in Zimmermann et al. ${ }^{22}$ To allow time for protein turnover, the cells were incubated for $24-72 \mathrm{~h}$ before proceeding with the rest of the experiment.

\section{RT-PCR}

S2 cells were treated with dsRNA as described above, and at various times after treatment total RNA was isolated using Trizol reagent (Invitrogen), according to the manufacturer's instructions. Total RNA $(3 \mu \mathrm{g})$ was used in a reverse transcriptase reaction with a gene-specific primer. From the resulting $50 \mu \mathrm{l}$ reaction, $2 \mu \mathrm{l}$ of cDNA was then used as a template in a PCR with nested primers specific for the sequence of interest. In each case, at least one of the primers used for PCR bound to untranslated sequence outside of the open reading frame sequence used to produce dsRNA.

\section{Caspase activity assay}

Caspase activity was measured using Ac-DEVD-afc (Enzyme Systems Products) as the substrate. To detect caspase activity in S2 cells that were depleted of cytochrome $c$, RNAi was performed as described and at $8 \mathrm{~h}$ after UV irradiation cells were harvested and spun down at $2000 \times g$. The cell pellets were resuspended in $100 \mu$ l Caspase Buffer $A$ and lysed by four cycles of freeze-thaw and incubated for $1 \mathrm{~h}$ at $37^{\circ} \mathrm{C}$. $0.2 \mu \mathrm{M} \mathrm{Ac}$ DEVD-afc was added and the reaction was mixed. The reactions were then analyzed fluorometrically (excitation $405 \mathrm{~nm}$, emission $535 \mathrm{~nm}$ ) and activity was expressed in relative arbitrary fluorescence units. To detect caspase activity in UV-treated cells, S2 or 293 cells were harvested as described above at various times after UV treatment and incubated with $0.2 \mu \mathrm{M}$ Ac-DEVD-afc. To detect caspase activity after treatment with the Hid peptide, untreated S100 extract was incubated with Hid or Met-Hid peptide for $4 \mathrm{~h}$ at $37^{\circ} \mathrm{C}$ and then caspase activity was determined as described above. To measure caspase activity in S2 or $293 \mathrm{~S} 100,25 \mu \mathrm{l}$ of treated S2 S100 or P10 fractions was added to $150 \mu$ l untreated S2 or 293 $\mathrm{S} 100$ and incubated at $37^{\circ} \mathrm{C}$ for $4 \mathrm{~h}$, and then caspase activity was determined.

To examine if mitochondria could enhance or accelerate caspase activity, $25 \mu \mathrm{l}$ of treated S2 S100 was added to $50 \mu \mathrm{l}$ of $\mathrm{P} 10$ and incubated at $37^{\circ} \mathrm{C}$ for $1 \mathrm{~h}$ followed by the addition of $150 \mu \mathrm{l}$ untreated S2 S100 and incubated at $37^{\circ} \mathrm{C}$ for $4 \mathrm{~h}$. Caspase activity was determined at various time points during the $4 \mathrm{~h}$ incubation. To determine caspase activity for recombinant $\mathrm{RHG}$ proteins, the procedure was identical to the above except that $0.25-100 \mu \mathrm{M}$ of Hid or Reaper was used instead of treated S2 S100.

\section{Viability assays}

To determine the viability with overexpressed Hid, Reaper, or Grim, $10^{6} \mathrm{~S} 2$ cells were treated with cytochrome $c$ dsRNA or negative control dsRNA corresponding to the bacterial chloramphenicol acetyl transferase (CAT) gene as described above. Cells were incubated for $72 \mathrm{~h}$ and then cotransfected using Cellfectin (Invitrogen) with plasmids expressing enhanced green fluorescent protein (eGFP) ( $3 \mu \mathrm{g})$ and either Hid, Reaper, or Grim $(3 \mu \mathrm{g})$. These plasmids have been described previously. ${ }^{39,40}$ The dsRNA was replaced following transfection (at the time of DNA addition) and $48 \mathrm{~h}$ after transfection, the number of viable green fluorescent cells was determined by counting three fields of view under $\times 400$ magnification, and a percent viability was calculated based on the number of eGFP-positive cells in untreated control cells transfected with plasmids encoding eGFP and CAT (set at 100\%). For UV viability, the cells were UV irradiated $24 \mathrm{~h}$ after transfection by placing the plates on a transilluminator for $10 \mathrm{~min}$. At $24 \mathrm{~h}$ after UV treatment, the number of viable, eGFP-positive cells remaining was determined as above and the percent viability was calculated relative to the number of eGFP-positive cells at $1 \mathrm{~h}$ after UV treatment. To determine the viability when S2 cells were treated with Hid, Reaper, or Grim dsRNA, $1 \times 10^{6}$ S2 cells were treated with dsRNA as described above and $24 \mathrm{~h}$ later the S2 cells were UV irradiated. At $24 \mathrm{~h}$ after UV treatment, the percent viability was determined as described above. For viability using the Hid peptide, $1 \times 10^{6}$ S2 cells were cotransfected with eGFP and $3 \mu \mathrm{g}$ of either Met-Hid peptide or Hid peptide and $48 \mathrm{~h}$ after transfection, viability was determined as described above. For experiments using caspase inhibitor, $100 \mu \mathrm{M}$ zVAD-fmk (Enzyme System Products) was added at the same time as the lipid/DNA mixture and maintained when the media was changed.

\section{Caspase cleavage assay}

$1 \times 10^{8}$ S2 cells were treated with cytochrome $c$ dsRNA, dronc dsRNA or both as described and UV irradiated. At $4 \mathrm{~h}$ after UV treatment, S2 cells were harvested in $1 \mathrm{ml}$ Caspase Buffer A and homogenized, and the P10, $\mathrm{P} 100$, and S100 fractions were isolated as described above. In total, $25 \mu \mathrm{l}$ of either fraction was incubated with $150 \mu$ of untreated S100 prepared from $2 \times 10^{9}$ cells for $4 \mathrm{~h}$ at $37^{\circ} \mathrm{C}$. To detect caspase cleavage in $\mathrm{S} 100$ treated with the Hid peptide, the procedure was similar except that Hid or Met-Hid peptide was incubated with untreated S100. An immunoblot was performed on $15 \mu \mathrm{l}$ of the sample using anti-DrICE antibody (obtained from Bruce Hay) at a concentration of $1: 2000$ and anti-rabbit IgG-HRP at $1: 10000$. To examine if cytochrome $c$ addition would induce caspase activation, $150 \mu \mathrm{l}$ of the $\mathrm{S} 100$ was incubated at $37^{\circ} \mathrm{C}$ for $4 \mathrm{~h}$ in the presence of $2 \mu \mathrm{g}$ of purified cytochrome $c$ (BD Biosciences), $2 \mathrm{mM}$ dATP and $1 \mathrm{mM} \mathrm{MgCl}$. To examine if mitochondrial factors would induce caspase activation, $150 \mu \mathrm{l}$ of $\mathrm{S} 100$ was incubated with $25 \mu \mathrm{l}$ of the P10 that was freeze-thawed four times and $15 \mu \mathrm{l}$ was analyzed by anti-DrICE immunoblot.

\section{Cytochrome $c$ detection}

$6 \times 10^{6}$ S2 cells were UV irradiated and at various times after UV treatment, the P10 and S100 fractions were isolated and $25 \mu \mathrm{l}$ was immunoblotted for cytochrome $c$ using $1: 1000$ anti-cytochrome $c$ antibody (BD Biosciences) and 1:7000 anti-mouse IgG-HRP. For Hid, Reaper, or Grim, $6 \times 10^{6} \mathrm{~S} 2$ cells were transfected with plasmids expressing Hid, Reaper, or Grim and $12 \mathrm{~h}$ after transfection $10 \mu \mathrm{l}$ of the P10 and $\mathrm{S} 100$ were analyzed for cytochrome $c$.

\section{Acknowledgements}

We thank Bruce Hay (California Institute of Technology) for kindly providing reagents. This work was supported by NIH grants R29 CA78602 from the National Cancer Institute, P20 RR107686 from the National Center for Research Resources (NCRR), P20 RR16475 from the BRIN Program of the NCRR, and by the Kansas Agricultural Experiment Station. This is contribution number 05-279-J from the Kansas Agricultural Experiment Station.

\section{References}

1. Thompson CB (1995) Apoptosis in the pathogenesis and treatment of disease. Science 267: 1456-1462

2. Vaux DL and Korsmeyer SJ (1999) Cell death in development. Cell 96: 245-254 
3. Shi Y (2002) Mechanisms of caspase activation and inhibition during apoptosis. Mol. Cell 9: 459-470

4. Garrido $C$ and Kroemer $G$ (2004) Life's smile, death's grin: vital functions of apoptosis-executing proteins. Curr. Opin. Cell Biol. 16: 639-646

5. Wang X (2001) The expanding role of mitochondria in apoptosis. Genes Dev. 15: $2922-2933$

6. Renatus M, Stennicke HR, Scott FL, Liddington RC and Salvesen GS (2001) Dimer formation drives the activation of the cell death protease caspase 9 . Proc. Natl. Acad. Sci. USA 98: 14250-14255

7. Liu X, Kim CN, Yang J, Jemmerson R and Wang X (1996) Induction of apoptotic program in cell-free extracts: requirement for dATP and cytochrome c. Cell 86: 147-157

8. Li F, Srinivasan A, Wang Y, Armstrong RC, Tomasselli KJ and Fritz LC (1997) Cell-specific induction of apoptosis by microinjection of cytochrome $c$ : Bcl-xL has activity independent of cytochrome $c$ release. J. Biol. Chem. 272: 3029930305

9. Li K, Li Y, Shelton JM, Richardson JA, Spencer E, Chen ZJ, Wang X and Williams RS (2000) cytochrome $c$ deficiency causes embryonic lethality and attenuates stress-induced apoptosis. Cell 101: 389-399

10. Abrams JM (1999) An emerging blueprint for apoptosis in Drosophila. Trends Cell Biol. 9: $435-440$

11. Srinivasula SM, Datta P, Kobayashi M, Wu JW, Fujioka M, Hegde R, Zhang Z, Mukattash R, Fernandes-Alnemri T, Shy Y, Jaynes JB and Alnemri ES (2002) sickle, a novel Drosophila death gene in the reaper/hid/grim region, encodes an IAP-inhibitory protein. Curr. Biol. 12: 125-130

12. Tenev $T$, Zachariou $A$, Wilson $R$, Paul $A$ and Meier $P$ (2002) Jafrac2 is an IAP antagonist that promotes cell death by liberating DRONC from DIAP1. EMBO J. 21: $5118-5129$

13. Salvesen GS and Abrams JM (2004) Caspase activation - stepping on the gas or releasing the brakes? Lessons from humans and flies. Oncogene 23 : 2774-2784

14. Fraser AG and Evan GI (1997) Identification of a Drosophila melanogaster ICE/ CED-3-related protease, drICE. EMBO J. 16: 2805-2813

15. Song Z, McCall K and Steller H (1997) DCP-1, a Drosophila cell death protease essential for development. Science 275: 536-540

16. Chen P, Rodriguez A, Erskine R, Thach T and Abrams JM (1998) Dredd, a novel effector of the apoptosis activators reaper, grim, and hid in Drosophila. Dev. Biol. 201: 202-216

17. Dorstyn L, Colussi PA, Quinn LM, Richardson H and Kumar S (1999) DRONC an ecdysone-inducible Drosophila caspase. Proc. Natl. Acad. Sci. USA 96 $4307-4312$

18. Rodriguez A, Oliver H, Zou H, Chen P, Wang X and Abrams JM (1999) DARK is a Drosophila homolog of Apaf-1/CED-4 and functions in an evolutionarily conserved death pathway. Nat. Cell Biol. 1: 272-279

19. Quinn LM, Dorstyn L, Mills K, Colussi PA, Chen P, Coombe M, Abrams JM, Kumar $S$ and Richardson H (2000) An essential role for the caspase DRONC in developmentally programmed cell death in Drosophila J. Biol. Chem. 275: 40416-40424

20. Kanuka H, Sawamoto K, Inohara N, Matsuno K, Okano H and Miura M (1999) Control of the cell death pathway by Dapaf-1, a Drosophila Apaf-1/CED-4related caspase activator. Mol. Cell. 4: 757-769

21. Varkey J, Chen P, Jemmerson R and Abrams JM (1999) Altered cytochrome $c$ display precedes apoptotic cell death in Drosophila. J. Cell Biol. 144: 701-710

22. Zimmermann KC, Ricci JE, Droin NM and Green DR (2002) The role of ARK in stress-induced apoptosis in Drosophila cells. J. Cell Biol. 156: 1077-1087
23. Dorstyn L, Mills K, Lazebnik $Y$ and Kumar S (2004) The two cytochrome $c$ species, DC3 and DC4, are not required for caspase activation and apoptosis in Drosophila cells. J. Cell Biol. 167: 405-410

24. Dorstyn L, Read S, Cakouros D, Huh JR, Hay BA and Kumar S (2002) The role of cytochrome $c$ in caspase activation in Drosophila melanogaster cells. J. Cell Biol. 156: 1089-1098

25. Olson MR, Holley CL, Gan EC, Colón-Ramos DA, Kaplan B and Kornbluth S (2003) A GH3-like domain in Reaper is required for mitochondrial localization and induction of IAP degradation. J. Biol. Chem. 278: 44758-44768

26. Chai J, Du C, Wu JW, Kyin S, Wang X and Shi Y (2000) Structural and biochemical basis of apoptotic activation by Smac/DIABLO. Nature 406: 855-862

27. Chai J, Yan N, Huh JR, Wu JW, Li W, Hay BA and Shi Y (2003) Molecular mechanism of Reaper-Grim-Hid-mediated suppression of DIAP1-dependent DRONC ubiquitination. Nat. Struct. Biol. 10: 892-898

28. Muro I, Means JC and Clem RJ (2005) Cleavage of the apoptosis inhibitor DIAP1 by the apical caspase DRONC in both normal and apoptotic Drosophila cells. J. Biol. Chem. 10.1074/jbc.M501206200

29. Lorenzo HK, Susin SA, Penninger J and Kroemer G (1999) Apoptosis inducing factor (AIF): a phylogenetically old, caspase-independent effector of cell death. Cell Death Differ. 6: 516-524

30. Du C, Fang M, Li Y, Li L and Wang X (2000) Smac, a mitochondrial protein that promotes cytochrome $c$-dependent caspase activation by eliminating IAP inhibition. Cell 102: 33-42

31. Verhagen AM, Ekert PG, Pakusch M, Silke J, Connolly LM, Reid GE, Moritz RL, Simpson RJ and Vaux DL (2000) Identification of DIABLO, a mammalian protein that promotes apoptosis by binding to and antagonizing IAP proteins. Cell 102: 43-53

32. Li LY, Luo $X$ and Wang $X$ (2001) Endonuclease $G$ is an apoptotic DNase when released from mitochondria. Nature 412: 95-99

33. Suzuki Y, Imai Y, Nakayama H, Takahashi K, Takio K and Takahashi R (2001) A serine protease, htra2, is released from the mitochondria and interacts with xiap, inducing cell death. Mol. Cell 8: 613-621

34. Hirel P-H, Schmitter J-M, Dessen P, Fayat G and Blanquet S (1989) Extent of $\mathrm{N}$-terminal methionine excision from Escherichia coli proteins is governed by the side-chain length of the penultimate amino acid. Proc. Natl. Acad. Sci. USA 86: 8247-8251

35. Holley CL, Olson MR, Colon-Ramos DA and Kornbluth S (2002) Reaper eliminates IAP proteins through stimulated IAP degradation and generalized translational inhibition. Nat. Cell Biol. 4: 439-444

36. Yoo SJ, Huh JR, Muro I, Yu H, Wang L, Wang SL, Feldman RMR, Clem RJ, Müller H-AJ and Hay BA (2002) Hid, Rpr and Grim negatively regulate DIAP1 levels through distinct mechanisms. Nat. Cell Biol. 4: 416-424

37. Muro I, Hay BA and Clem RJ (2002) The Drosophila DIAP1 protein is required to prevent accumulation of a continuously generated, processed form of the apical caspase DRONC. J. Biol. Chem. 277: 49644-49650

38. Wright CW and Clem RJ (2002) Sequence requirements for Hid binding and apoptosis regulation in the baculovirus inhibitor of apoptosis Op-IAP: Hid binds Op-IAP in a manner similar to Smac binding of XIAP. J. Biol. Chem. 277: 2454-2462

39. Vucic D, Sechagiri S and Miller LK (1997) Characterization of Reaper- and FADD-induced apoptosis in a lepidopteran cell line. Mol. Cell. Biol. 17: 667-676

40. Vucic D, Kaiser WJ and Miller LK (1998) Inhibitor of apoptosis proteins physically interact with and block apoptosis induced by Drosophila proteins HID and GRIM. Mol. Cell. Biol. 18: 3300-3309

\section{Supplementary Information accompanies the paper on Cell Death and Differentiation website (http://www.nature.com/cdd)}

